\title{
Myths, Safety and Awareness of Lightning Protection in Bangladesh
}

\author{
Md Rosaidul Mawla ${ }^{1, *}$, Nasrin Sultana ${ }^{2}$, MSAAF Shiblee ${ }^{1}$ \\ ${ }^{1}$ Department of Electrical, Electronic \& Communication Engineering, Military Institute of Science and Technology (MIST), Dhaka, \\ Bangladesh \\ ${ }^{2}$ Department of Community Medicine, Shaheed Taj Uddin Ahmad Medical College, Gazipur, Bangladesh
}

Email address:

mawla71@yahoo.com (Md R. Mawla)

${ }^{*}$ Corresponding author

\section{To cite this article:}

Md Rosaidul Mawla, Nasrin Sultana, MSAAF Shiblee. Myths, Safety and Awareness of Lightning Protection in Bangladesh. International Journal of Electrical Components and Energy Conversion. Vol. 6, No. 2, 2020, pp. 7-13. doi: 10.11648/j.ijecec.20200602.11

Received: July 30, 2020; Accepted: August 17, 2020; Published: November 4, 2020

\begin{abstract}
Bangladesh, being a tropical country, experiences relatively high density of lightning each year. Lightning has been identified as one the major causes of weather-related deaths and injuries in Bangladesh. The government of Bangladesh has declared lightning as natural disaster when 81 people have lost their lives in just two days due to lightning in 2016. Lightning is a source of fearfulness, inquisitiveness, inspiration and panic. As number of death has increased in Bangladesh in lightning, so the safety rules for the installation of lightning prevention system which is a mandatory provision under Bangladesh National Building Code, to be followed for building construction. People of low literacy rate have the tendency to violate more, the basic lightning safety guidelines. Hence, awareness program has started to educate the people especially the rural one. However, a survey has been conducted to find out the common myths, beliefs, misconceptions in Bangladesh and its impact on lightning safety. It summarizes the prevailing lightning safety awareness and education around the world. Finally, it puts forward some ray of light about the suggestions about lightning protection, safety and awareness for Bangladeshi people to curb the myths and misconceptions.
\end{abstract}

Keywords: Lightning, Lightning Myths, Lightning Misconceptions, Lightning Safety

\section{Introduction}

Bangladesh is often said to be one of the most vulnerable countries of the world in terms of natural and anthropogenic hazards. As per the "World Risk Report 2015," Bangladesh has been identified as sixth most natural disaster-prone country among 173 countries in the world [1]. The geography and climate have made the country vulnerable to different meteorological, hydrological and geological hazards. It is low lying deltaic country covering an area of about 1,47,570 sq. $\mathrm{km}$. with population nearing 164 million and a density of 1,237 people $\mathrm{m}^{2}$ [2]. Developing countries have long lists of problems like illiteracy, disease, hunger, corruption. There's one more problem that has given less attention, until recently lightning strikes, which cause a disproportionately high number of deaths in developing countries [3]. The climate of Bangladesh is tropical monsoon climate characterized by seasonal variation in rainfall and wind pattern. During Southwest monsoon (rainy season) i.e June-September, Bangladesh receives heavy rain. The frequency and intensity of natural disasters have been increased in recent years due to climate change. Lightning injury has been identified as one the major causes of weather-related deaths in Bangladesh. In response to the lightning event in 2016, when 81 lives were lost in just two days due to lightning, the government of Bangladesh has declared lightning a natural disaster [4]. Lightning is a source of awe, curiosity, inspiration and fear. The brilliance, power and destructive capacity of lighting have made it the subject for religion, superstition, politics, and, most recently, scientific investigation [5]. Lightning is an electrical energy while thunder is a sound energy. Both occur at the same time during a thunderstorm, but since light travels faster than sound, lightning is seen first before one can hear the sound of thunder. Lightning is fast and very hot while thunder can usher in heavy rain and strong winds, but 
lightning is more dangerous and destructive than thunder. According to the National Geographic, lightning storms in Bangladesh occur mostly in May and in the afternoon, when the temperature is high $[3,6,7]$. According to, Vaisala Press Release April 18, 2018, Vaisala Releases Global Lightning Data Strokes from 2013 through 2017-With nearly 9 billion strokes counted, that adds up to more than one stroke for every person living on Earth. From 2013 to 2017, Vaisala tracked 8,761,390,744 lightning strokes around the world. This unique dataset helps meteorologists develop timely and accurate forecasts and warnings at an unprecedented global scale.

Lightning physics is complex, but all lightning begins with a thunderstorm. A thunderstorm develops when the sun heats pockets of air that cause those pockets to rise in columns which eventually form clouds. Within these clouds, layers of precipitation develop such as ice, hail, rain, which based on their weights, stratify to different layers in the cloud. Rising warm air with falling ice particles results in collisions between the different particles. This creates charge, and eventually the top of the cloud becomes predominantly positive and the bottom of the cloud negative [8-9]. The earth is generally negatively charged, but when storm clouds roll over, the negatively charged bottom of the cloud induces the earth to take on a positive charge $[5,9,10]$. When the separation of charge becomes too much (a difference in voltage between the cloud and the ground or object exceeds 2 1 million volts per minute), the result is lightning $[9,10,11]$. Lightning reaches the earth in more than 100 times per second or 8 million times a day [12]. The chance of being struck by lightning depends on population density and landscape features, which may either protect or expose people to being hit [1].

Spreading lightning safety information to general public has become an ethical duty among lightning researchers around the globe because lightning injury is still a latent global threat. Lightning is the second leading cause of weather-related death in much of the world [1]. Main cause of lightning accidents in the region is the lack of awareness and below-average living conditions of the people driven by the poverty of the region. In other word, injuries and deaths are basically due to both lack of awareness and absence of proper protection and safety schemes. For many communities in rural areas even such low-cost solutions may be unaffordable. Therefore government intervention in installing lightning protection schemes is very vital. The objective of this paper is to provide lightning awareness education that reaches the maximum possible number of people with information regarding personal safety during lightning storm.

\section{Methodology}

The study was a mixed method study using both quantitative and qualitative data. A cross-sectional study was conducted to understand the misconceptions and awareness of the lightning in Bangladesh. In addition, different literatures are searched. Qualitative data related to lightning awareness and misconceptions in Bangladesh were collected to get the actual information of lightning injuries in Bangladesh. A statistical survey was considered to different places of the country from rural to city.

Data collection is an important part of any survey because it affects the survey result seriously. Considering that questionnaire were developed in a befitting manner. Prior to data collection, trained interviewers had visited the selected areas and explained the study objectives and ethical issues. They then conducted the questionnaire survey. A number of interviews were held at various social and educational levels. Interviews were most often supplemented by unbiased questionnaires prepared according to accepted sociological norms and also by oral discussions. Even tribes are also interviewed.

Gathered information was cross-examined for the accuracy by various means. Information gathered were analysed and compiled to get the actual public reflection about the lightning misconceptions. The outcome of the study is used to develop a set of feasible recommendations for countries to educate the people about lightning hazards.

\section{Result and Discussion}

\subsection{General Information About Surveyed Population}

Team asked question to $51 \%$ male and $49 \%$ female in all locations. Out of $51 \%$ male, $40.30 \%$ is from rural, $37.51 \%$ is from urban and $22.39 \%$ from city. Similarly out of $49 \%$ female, $38.51 \%, 39.68 \%$ and $24 \%$ from rural, urban and city respectively. Again, out of $51 \%$ male, $37.31 \%$ population is of $20-35$ of age, $46.27 \%$ is of $34-50$ years of age and $16.42 \%$ is of above 50 years age. For, $49 \%$ female, $39.68 \%$ population is of $20-35$ years age, $46.03 \%$ is of $34-50$ years age and $14.29 \%$ is of above 50 years age. Literacy rate of the survey population is $30 \%$ is illiterate, upto class V is $24.62 \%$, from class VI to $\mathrm{X}$ is $21.00 \%$, Secondary School Certificate (SSC)/Higher Secondary Certificate (HSC) is $20.00 \%$ and graduate to above is $4.38 \%$. In rural area, occupation of male is farmer/daily /labour $18.52 \%$, shop keepers is $35.19 \%$, Business/ Small to Medium Enterprise (SME) is 16.66, service is $22.22 \%$, others is $7.41 \%$ and female is housewife is $60.87 \%$, shopkeepers is $15.21 \%$, Business/SME is $10.87 \%$, service is 8.70 and others $4.33 \%$. Similarly In urban area, occupation of male is farmer/daily /labour $8.00 \%$, Shop keepers is $24.00 \%$, Business/ SME is $52.00 \%$, service is $24.00 \%$, others is $12.00 \%$ and female is housewife is $32.00 \%$, shopkeepers is $16.00 \%$, Business/SME is $24.00 \%$, service is $20.00 \%$ and others $8.00 \%$. In metropolitan city area, occupation of male is Rickshaw Pullar/daily /labour 6.68\%, Shop keepers is $13.33 \%$, Business/ SME is $33.33 \%$, Service is $33.33 \%$, others is $13.33 \%$ and female is housewife is $14.33 \%$, shopkeepers is $6.68 \%$, Business/SME is $26.66 \%$, Service is $4.00 \%$ and others $13.33 \%$. Figure 1 represents the literacy rate of population of survey areas. 


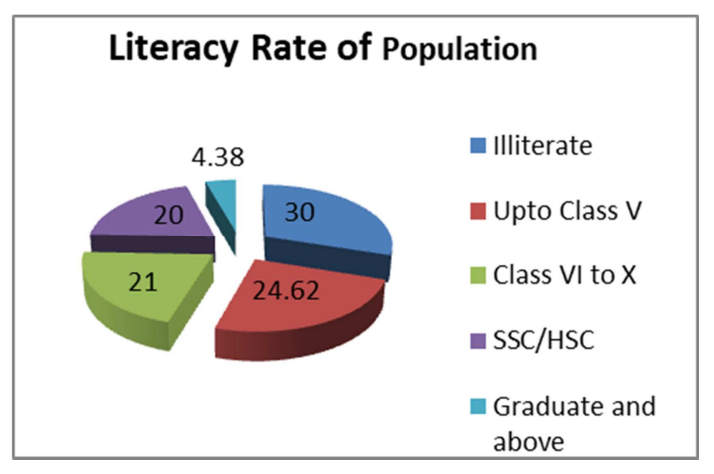

Figure 1. Literacy rate of population of survey areas.

\subsection{Surveyed Results on Misconceptions About Lightning}

As per, Bangladesh Disaster-Related Statististics-2015 by BBS, from 2009-14, thunderstorm is the third highest disaster which affect 14.94\% household of Bangladesh. According to the locations, survey was carried out [2]. Figure 2 shows the affected household by disasters from 2009-2014.

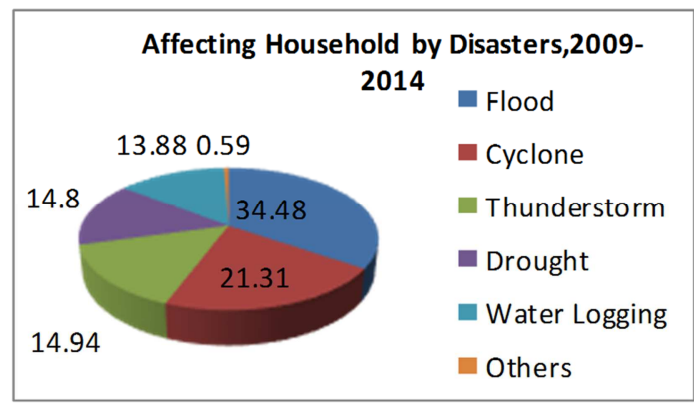

Figure 2. Affected household by disasters from 2009-2014.

Surveyed was undertaken randomly at villages \& upazillas to metropolitan city corporations, plain land to hilly areas. People of different religion and people from hilly areas are also interviewed to get the real picture. It was found that there are many misconceptions which have no scientific base. In the survey, there are as many as ten main misconceptions are highlighted. They are lightning kills only the sinners, it is light of God, without raining there is no danger of lightning, rubber tires or rubber soled shoes protect human from lightning, lightning never strikes the same place twice, metal attracts lightning, cell phone also attracts lightning, running decreases the chances of strike of lightning, tall objects are safe for lightning, lightning victims are dangerous to touch, etc.

After being educated, a good number of population still believe those superstations. In the location base survey both male and female used to believe that lightning kills the sinners or bad people. Percentages in rural area for male is $91.84 \%$ and female is $93.91 \%$, in urban area for male is $70.12 \%$ and female is $81.40 \%$, in metropolitan area for male is $57.67 \%$ and female is $61.67 \%$. Succeeding to that, tall tress safe humans from lightning strikes are the second popular (male in rural area is $1.36 \%$, urban area is $4.84 \%$, city area is $5.13 \%$ and female in rural area is $1.00 \%$, urban area is $2.56 \%$, city area is $3.53 \%$ ) misconceptions of lightning. The myths of lightning is projected at table 1.

Table 1. List of Myths of Lightning.

\author{
Kills bad people \\ Light of God \\ No danger without raining \\ Rubber tires or rubber soled shoes protect from lightning \\ Lightning never strikes the same place twice \\ Metal attracts lightning \\ Cell Phone attracts lightning \\ Running decreases the chances of strike of lightning \\ Tall objects are safe for lightning \\ Lightning victim is dangerous to touch
}

An interesting result from the location based survey is marked that from rural to city area the concepts of lighting (male in rural area is $0.56 \%$, urban area is $2.20 \%$, city area $14.20 \%$ and for female in rural area is $0.22 \%$, urban area is $1.12 \%$, city area $9.20 \%$ ) is increased for both male and female. Again another interesting misconception is marked when surveyed according to age. It is noticed that aged people believe more in superstation in lightning. According to the data for male aging from 20-35 years of age, 58.80\% believe sinners are being punished by lightning, whereas 35 50 years of age, this percentage is $66.87 \%$ and above 50 years of age, this misconceptions are even more, i.e $81.00 \%$ for female again, for 20- 35 years of age, it is $64.92 \%, 35-50$ years $75.66 \%$ and above 50 years $84.66 \%$. Furthermore, female believe in superstation more. In education base study the same concepts are reflected. Here the illiterate $(85.90 \%)$, upto class V $(79.69 \%)$, from class VI to X $(69.05 \%)$, SSC/HSC (51.15\%) and graduate and above (30.35\%) believe that sinners are punished by lightning. Educated people believe less even then a good percentage has misconceptions about lightning. But encouraging is that educated society has less misconception on lightning. Again the tribes has one or two different misconceptions which was not found in survey like mirror repels the lightning

About lightning safety, almost $80 \%$ of the surveyed people have more or less knowledge of basic lightning safety. The majority people are well aware of lightning dangers and workable knowledge on the safety guidelines. Daily labour, farmers, rickshaw puller, fishermen or any other person working in open space are very much conversant about the lighting safety, but they do not pay serious attention to them. Because their masters do not allow them to take shelter on adverse weather or they are not willing to take shelter as they have to earn money by labor to feed his family or they think it will not be happen to them. But peculiarity is that people took part in the survey stated that they take precautions to protect their household equipment (by plugging off them during thunderstorm periods), but they do not leave or postponing their outdoor activities as a thunderstorm is approaching. However, a good percentage of people are still ignorant about the lightning safety guidelines equally observed in both rural and urban communities.

About lightning awareness, around 90\% interviewers admitted that government has better forecasting and monitoring about weather and climate change than before. Some people 
admitted that government telecasts the weather forecast in TV channel, radio and print media also plays pivotal role in this aspect. Further, a good percentage of people acknowledge in city area that conference, seminar, workshop etc. are being conducted timely to enhance awareness.

\section{Likely Causes of Lightning}

Lightning happens mostly when clouds clash with each other and air pollution is also a factor. Lightning is high in the month of Boishakh (April-May), when there is higher dust and carbon in the air and casualties are mostly in areas where people work in open fields mostly, particularly in haor region. Already scientists have cautioned that due to climate change and global warming, lightning storms have increased drastically. Because the global warming which produces more water evaporation, increasing cloud formation, the amount of rainfall are the potential ingredients for lightning storms $[3,6]$. Further, Climatologists assume that there would be more explosive lightning events rather than a gradual increase because the world warms up. According University of Berkeley study in 2014, for every degree Celsius of warming lightning strikes is estimated to increase by 12 per cent and it will rise 50 per cent by the end of the century. Therefore, drastic climate change is one of the principal elements of occurring frequent lightning deaths all over the world.

Now a days in Bangladesh, the number of fatal lightning strikes have increased due to population growth and deforestation specially disappearance of many tall trees. Further, the lightning related deaths in Bangladesh have increased mainly due to ignorance about lightning. Because often the metal farm equipment is kept in open fields, people stands near metal cell phone towers or electrical power towers, taking shelter under trees during electrical storms, etc.

\section{Action Taken by Government}

\subsection{Installation of Lightning Detector}

Lightning is one of the leading causes of death related to environmental disaster. Clearly, prevention of these highly lethal injuries are paramount. A high level of precaution for individuals working or performing other activities outdoors during the thunderstorm season must be observed. Therefore, Bangladesh government has taken due attention to install the advanced technology of weather and climate change forecasting and monitoring related equipment and also taken adequate care for capacity building. Eight sensors are installed at lightning prone areas like Chittagong, Tentulia in Panchagarh, Badalgachi in Naogaon, Mymensingh, Sylhet, Khulna's Kayra and Patuakhali. These eight sensors are capable to provide early warnings 10 to 30 minutes ahead on incidents of lightning. This will allow people to know when the incidents might occur in specific areas which will reduce the loss of lives [13]. Figure 3 and figure 4 represent the installed lightning detector and the coverage area of lightning detector in Bangladesh respectively.

\subsection{Other Steps to Improve Disaster}

To provide timely and comparatively perfect weather forecast and warning signals, Bangladesh Meteorological Department (BMD) is equipped with Weather Research and Forecasting (WRF) model, Non Hydrostatic Model (NHM), ECMWF Numerical Model Product Visualized by DIANA (Digital Analysis) and Tseries. Further, to get the cyclone forecast, Bangladesh is using modern Storm Model (IIT-D Ges MRI Model) and wave model which is also used by World Meteorological Organization (WMO). WMO is also implementing Coastal Inundation Forecasting Demonstration Project for Bangladesh (CIFDP-B) to get timely cyclone forecast. Norwegian Meteorological institute (Met. no) is assisting to implement a project name "Institutional Support and Capacity Building for Mitigation of Weather and Climate Hazards in Bangladesh" for capacity building in weather forecasting and climate change modeling. Besides those, Asian Disaster Preparedness Centre (ADPC) and RIMES is assisting in capacity building of BMD through weather and climate related training/seminar in every year [14].

\section{Lightning Detector}

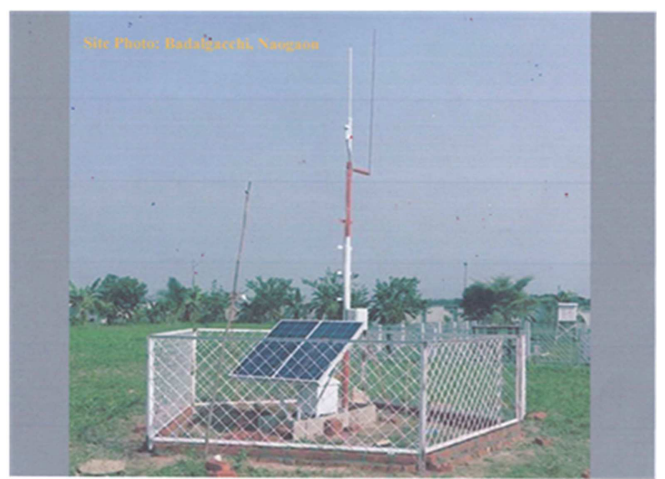

Figure 3. Installed Lightning detector in Bangladesh.

\section{Coverage area of lightning detector}

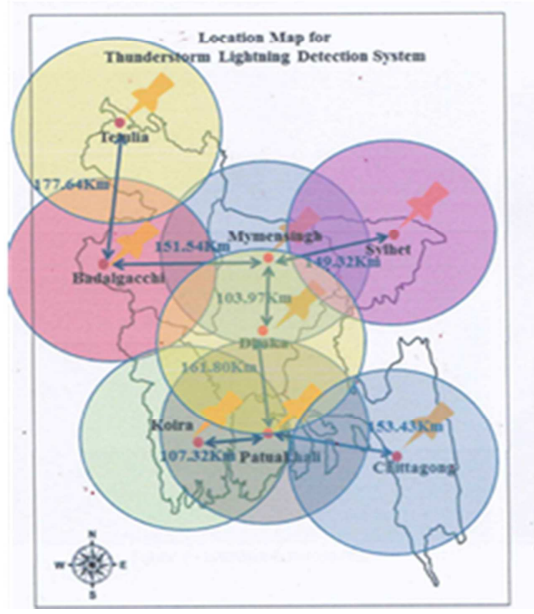

Figure 4. Coverage area of lightning detector in Bangladesh. 


\subsection{Introduction of BMD Weather Apps}

BMD has introduced a mobile application 'BMD Weather App'. It will provide all daily and updated weather information for smart phone users. This application will project the latest weather data like air temperature, air pressure, direction, amount of rain, from the automatic weather monitoring centers situated in various parts of the country. The latest information on air temperature, air pressure, direction, amount of rain also can be immediately known through using the application. In addition, through this developed app, the cautionary signals regarding cyclones, earthquake, hydrology, agricultural weather, cold wave and draught related information can be intimated. [14-15].

\section{Lightning Safety}

Lightning injuries are largely avoidable by taking certain precautions. Lightning safety recommendations identify two reliable safe places. One is inside a large enclosed building. The other safe location is inside a fully-enclosed metal-topped vehicle [16]. Two thirds of lightning injuries occur outdoors [17]. People work outside like farming and field labour, construction and building maintenance activities, pipefitting or plumbing, telecommunications field repairing works and power utility field repairing activities are most vulnerable in Bangladesh during the lightning strikes as these people do not have immediate protection in lightning. Therefore it is an urgent requirement to have at least one building for a village or community so that they can gather inside the building during thunderstorm period. The mass gathering places like schools, hospitals, supermarkets, government office complexes, religious places etc. should compulsorily be safeguarded by a lightning protection system designed and guideline.

Lightning is associated with cumulonimbus clouds, but may travel many kilometres in front of a thunderstorm even in clear sky. Therefore, the beginning and end of a storm are the most dangerous times and the " $30-30$ " rule is very effective. As per the " $30-30$ " rule, there is a danger of being struck when the interval between seeing the lightning and hearing the thunder is less than $30 \mathrm{~s}$ (flash to- thunder time). Individual should not continue climbing until $30 \mathrm{~min}$ have elapsed after seeing the last lightning and hearing the last thunder [18]. Therefore, lightning injury can still persist after a storm has passed or even in sunny conditions and one should wait at least 30 minutes from the most recent thunder clap or lightning sighting before resuming activities. If one stay in a building, he/she must refrain from touching electrical power, water, sewer services, metal surfaces and keep the doors and windows closed during lightning strike.

Trees or tall objects, high ground, open spaces, metal objects and ungrounded buildings such as shacks and huts should be avoided. In particular, some individuals increase their risk of injury by erroneously seeking shelter under isolated trees during thunderstorms. Further, during a thunderstorm, electrical appliances should be turned off and one should refrain from using telephone. If it is not possible to take shelter, then one should insulate oneself from ground and minimizing points of contact. In a forest, one should seek a low area under a thick growth of saplings or small trees. If someone is on the water, he/she should seek shore. During thundering, one should avoid swimming and boating. It is practised that moving under a bridge or cliff while in the boat might afford some protection. Sailboats and powerboats should be protected with lightning rods and grounding equipment attached to a metal keel or understructure of the boat.

The installation of lightning prevention system, a mandatory provision under Bangladesh National Building Code, is to make people safe in urban areas. For rural areas, where vulnerability is high, the suggested awareness creation on an extensive level, in addition to planting of trees to avoid casualties. Lightning Arrestors should be installed on electric power systems and telecommunication systems to protect the insulation and conductors of the system from the damaging effects of lightning.

\section{Suggestive Measures for Lightning}

Lightning is a bright flash of electricity produced by a thunderstorm. It is also one of the most erratic and unpredictable characteristics of a thunderstorm. All thunderstorms produce lightning and are very dangerous. Because of this, no one can guarantee an individual or group absolute protection from lightning. People of low literacy rate have the tendency to violate the basic lightning safety guidelines. Such negligence is due to lack of awareness, no motivation to follow even known safety rules and poverty. Poor people have the lack of interest to stop the work at outside even under thunderstorm conditions. This is because of the low level of literacy. So steps should be taken to increase the literacy rate and extensive awareness programs on lightning safety should be conducted especially at rural level.

The primary aim of the lightning safety awareness is to aware people about the dangers of lightning. Though lightning awareness programs started in Bangladesh in 2004, but did not gain much momentum. Initially, this program was planned for school teacher with a consideration that they will be able to disseminate the same to the students, related guardians and local community. Later it was assessed that it was not very effective in rural areas owing to poor literacy rate. Therefore, the Bangladesh Lightning Awareness Centre has initiated few more methods to educate and disseminate knowledge among the general mass. At the very lower level it is planned to educate people through folk songs, dramas, road-side stage plays, dances and storytelling. At the next level, it is planned to aware people by conducting studentteacher seminars and distributes brochures, handouts and booklets etc. and also use print and electronic media and wallpaper articles. In few occasions, in cities billboard displays are used and awareness centre also conducts seminars and technical sessions on lightning where foreign experts are integrated to their support. The government of Bangladesh can play a strategic role by planting palm trees across the whole country. Short documentary films or TV 
clips, speeches, presentations, seminar, workshop and educational programs at higher societal layers, motivational speech at religious places and community gatherings and door to door visiting by an expert panel or social activist may be effective way to aware general mass. There should be adequate and easily accessible medical facilities, emergency care and fast transportation even in remote areas to address the lightning affected patients. There should be strict adherence of Bangladesh National Building Code by the government. Recently, lightning awareness promotion has also been launched through internet; especially by means of social networking such as Face book, Blog posts, personal web sites etc.

Lightning is considered the third leading cause of affecting household by disaster in Bangladesh. As lightning also inflicts life-long debilitating injury on many more than it kills, the outcome of the injury and its impacts on a family can have high impact when included in educational efforts. Location, timing, lightning casualty demographics, local application and other motivational factors can also be used to increase the interest in lightning safety. Bangladesh newspapers and magazines should frequently published articles highlighting the dangers of lightning especially when reporting a lightning death or injuries to a large group of people. The amount of advice about the lightning risk awareness and safety advice increased greatly due to the growth of public radio stations and television sets for their publicity.

The accuracy of weather forecasts by the Bangladesh Meteorological Department is an important to have faith on its forecast. So enhancement of rapid advanced technology is essential to enable the running of sophisticated numerical forecast models precisely. In recent years, 'BMD Weather App' to facilitate smart phone users to get all daily information services and keeps update about weather.

In any safety procedure, avoiding the risk is best. Outdoor activities should be scheduled to avoid the lightning threat. People should be taught to plan ahead; use the weather forecast and know their local weather patterns. Engineers may endeavour to develop creative solutions replacing the existing one in lightning protection by using modern technology which is financially viable lightning protection designs for small houses in communities where affordability is a major issue. Government should encourage such efforts.

\section{Conclusion}

Lightning is persistently one of the leading causes of death caused by environmental or natural disaster. There is a dearth of lighting education especially in rural area. Therefore, ignorance kills people. It is important to change the minds of people with different cultural belief systems and to educate them on the scientific facts about lightning. Motivation on lightning safety education is quick, easy and inexpensive and can be communicated effectively. Lightning safety education needs to be correct, consistent, credible, easy to use, easy to remember and interesting to learn. There should be improved forecast models for thunderstorms and more accurate and timely warnings of lightning, installation of lightning location detection systems, advances in the medical treatment of lightning casualties within and outside of hospitals and greater public awareness of the lightning threat and knowledge of what actions to take to minimize exposure to the lightning risk. Awareness can be enhanced by various programs and practice can be regular by strict regulations and guidelines by the government. Government should be very firm in instituting building codes consistent with accepted lightning codes. Engineers need to be updated on the latest technology about lightning and make an endeavour to innovate lightning protection system which will be inexpensive, easily installed and low maintenance.

\section{Acknowledgements}

I am thankful to Military Institute of Science and Technology for providing me with positive environment for conducting this research.

\section{References}

[1] Mawla M. R, Shiblee MSAAF, Khan M. Z. R., Mamun M. M. H., Hasan M. M., and Sultana N., 'Statistical Analysis of Lightning Myths and Suggestive Measures in Context of Bangladesh', $4^{\text {th }}$ International Conference on Electrical Engineering and Information \& Communication Technology, 22-24 September, 2018, pp 666-671.

[2] Bangladesh Bureau of Statistics (BBS) (2016), Bangladesh disaster-related statistics 2015: climate change and natural disaster perspectives, Ministry of Planning, BBS, Dhaka.

[3] Quinn M, "Death by Lightning a Danger in Developing Countries", National Geographic, 04 November 2013.

[4] Animesh Biswas, Koustuv Dalal, Jahangir Hossain, et al, "Lightning Injury is a disaster in Bangladesh?-Exploring its magnitude and public health needs" F1000Research 2016, Latest published: 29 Dec 2016, 5: 2931 (doi: 10.12688/f1000research.9537.1).

[5] O'Keefe Gatewood M, Zane RD, "Lightning injuries". Emerg Med Clin North Am. 2004; 22 (2): 369-403.

[6] Islam S, "Bangladesh declares lightning strikes a disaster as deaths surge", Reuters, dated 22 June 2016, Available at: https://in.reuters.com/article/bangladesh-lightningdisaster/bangladesh-declares-lightning-strikes-a-disaster-asdeaths-surge-idINKCN0Z81U4 (Accessed on 17 June 2018).

[7] Dewan, A., M. Hossain, M. Rahman, Y. Yamane, and R. Holle, 2017: Recent Lightning-related fatalities and injuries in Bangladesh. Wea. Climate Soc. doi: 10.1175/WCAS-D-160128.1, in press.

[8] http://huginonline.ie/2018/04/18/Vaisala+Releases+Global+Li ghtning+Data+Strokes + from+2013+through $+2017+$ HUG2184 824.html (Accessed on 31 May 18).

[9] John McCarthy, MD, Tropic Lightning: Myth or Menace? PMCID: PMC4244891, Hawaii J Med Public Health. 2014 Nov; 73 (11 Suppl 2): 44-47. 
[10] National Weather Service, author. Lightning safety: understanding lightning. [January 18, 2014]. Available at: http://www.lightningsafety.noaa.gov/science/scienceoverview.htm.

[11] Ritenour AE, Morton MJ, Mcmanus JG, Barillo DJ, Cancio LC. Lightning injury: a review. Burns. 2008; 34 (5): 585-594.

[12] Okafor UV, “ Lightning and acute renal failure: a review”, Ren Fail 2005; 27: 129-34.

[13] The Daily Sun, "Bangladesh's first lightning forecast system soon", Dated 13 May 218. Available at: http://www.dailysun.com/home/printnews/308557.

[14] Brochure of Bangladesh Meteorological Department, www.bmd.gov.bd.
[15] "Weather Information Technology", by Bangladesh Meteorological Department (BMD), 2016.

[16] Holle, R. L., R. E. López, L. J. Arnold, and J. Endres, 2008b: Lightning-caused deaths and injuries in the vicinity of vehicles. Preprints, 3rd Conf. on Meteorological Applications of Lightning Data, January 20-24, New Orleans, LA, Amer. Meteor. Soc., 10 pp.

[17] Elsom D. Deaths and injuries caused by lightning in the United Kingdom: analyses of two databases. Atmospheric Research, 2000; 56 (5): 325-334. DOI: https://doi.org/10.1016/j.ijdrr.2018.06.001.

[18] Holle RL, L'opez RE., Updated recommendations for lighting safety-1998, Bull Meteorol Soc 1999; 18: 2035-41. 